\title{
APRENDENDO SIMETRIA COM ESPELHOS E CALEIDOSCÓPIOS: UMA AULA INTERDISCIPLINAR ${ }^{1}$
}

\author{
Bruno Tizzo Borba \\ Universidade Federal de Uberlândia \\ brunotborba@gmail.com \\ Maria Teresa Menezes Freitas \\ Universidade Federal de Uberlândia \\ mtmfreitas@gmail.com
}

Resumo: O texto relata uma experiência que averiguou os benefícios do uso de espelhos planos e caleidoscópios em aulas de Geometria como recurso pedagógico no processo de ensino aprendizagem de alunos $8^{\circ}$ ano do Ensino Fundamental. A proposta inclui uma aula interativa e manipulativa envolvendo conceitos de simetria, analisando as contribuições dos objetos didáticos do ponto de vista geométrico e artístico ao se explorar os conceitos de forma interdisciplinar em aulas de Geometria e Educação Artística. A abordagem metodológica utilizada na construção dos Espelhos e dos Caleidoscópios é relatada no texto, bem como todos os recursos envolvidos no desenvolvimento das aulas. Destacou-se a potencialidade da dinâmica adotada no processo, relacionando com a teoria das representações semióticas. Observou-se que os alunos se envolveram nas aulas e desenvolveram com destreza a noção de simetria do ponto de vista geométrico e artístico, evidenciando os benefícios dos recursos utilizados no processo de ensino e aprendizagem.

Palavras-chave: Simetria; Representação Semiótica; Interdisciplinaridade.

\section{Introdução}

O presente relato refere-se a uma proposta de ensino cujo tema principal é a simetria e suas classificações, evidenciando a potencialidade de uma aula interativa e manipulativa de Geometria. A proposta foi elaborada e desenvolvida em duas turmas do $8^{\circ}$ ano do Ensino Fundamental ( $8^{\text {os }}$ B e C) de uma Escola Municipal de Uberlândia - MG no ano de 2015. Ressalta-se que estas turmas por razões diversas não tiveram a oferta do conteúdo de Geometria no ano anterior ( $7^{\circ}$ ano).

Estabeleceu-se uma parceria entre o professor pesquisador, primeiro autor, com a professora de Educação Artística dessa mesma escola. Logo, esse trabalho desenvolveu-se de forma interdisciplinar e colaborativa.

No que se refere à Matemática, levou-se em conta um dos objetivos para o segundo ciclo do ensino fundamental que, segundo os Parâmetros Curriculares Nacionais (BRASIL, 1998), inclui a identificação de características das figuras geométricas, percebendo

\footnotetext{
${ }^{1}$ Versão similar deste texto foi apresentado no XII Encontro Nacional de Educação Matemática (2016).
} 
semelhanças e diferenças entre as mesmas, por meio de composição e decomposição, simetrias, ampliações e reduções. No eixo temático de Espaço e Forma o documento reforça a importância do estudo de simetria na identificação de semelhanças e diferenças entre polígonos, usando critérios como eixos de simetria.

Esse assunto, também é citado nos conteúdos atitudinais apresentado no documento, orientando a necessidade da sensibilidade para observar simetrias, na natureza, nas artes, nas edificações. Ainda se apresenta a necessidade de se adquirir a percepção da simetria como característica de algumas figuras e não de outras.

Acredita-se que para o aluno aprender matemática com significado seja fundamental que ele aprenda com compreensão e atribuindo sentido ao que aprende. Para tal será importante que o aluno saiba o porquê das coisas, e não simplesmente memorize conceitos e propriedades. Com o intuito de valorizar o conhecimento prévio do aluno e o instigar a pensar logicamente, relacionando ideias, descobrindo regularidades e padrões, estimulando sua curiosidade, seu espírito de investigação e a sua criatividade, ficamos motivados a planejar a aula relatada neste texto.

Assim, a expectativa da proposta era que os alunos participantes pudessem:

$>$ Criar e observar os possíveis polígonos, formas geométricas e artísticas;

$>$ Manipular os objetos didáticos e averiguar as simetrias;

$>$ Reconhecer as diferentes classificações simétricas, com seus possíveis eixos de simetria;

$>$ Investigar uma possível relação entre os ângulos centrais e os polígonos.

Para contemplar os objetivos almejados, perseguimos uma pergunta norteadora que pudesse auxiliar na condução do trabalho alvo de estudo. Dessa forma, a pergunta guia foi assim redigida: quais as possibilidades de elaboração de uma proposta de ensino que viabilize uma aula interativa e manipulativa que envolva os conceitos de simetria, utilizando espelhos e caleidoscópios?

Tento esta meta em mente algumas referências contribuíram para guiar o planejamento das aulas, especialmente pesquisas que apresentam propostas de ensino, e incluem embasamento histórico sobre o assunto.

\section{Alçando voos...}


Alguns autores como ALMEIDA (2003), MARTINS (2003) e MURARI (1999), nos relatam que instrumentos como espelhos e caleidoscópios são realmente interessantes, provocadores de envolvimento e causadores de interesse e participação dos alunos nas aulas de geometria.

Na busca por entender a razão desses recursos serem citados como eficazes no ensino do conceito de simetria encontramos Batistela (2005) que nos relata a respeito do fenômeno da reflexão que um espelho pode proporcionar no processo de formação de conceitos geométricos.

\begin{abstract}
O fenômeno da reflexão que obedece às leis da reflexão da ótica geométrica faz com que, dada uma figura qualquer num plano, colocada à frente e perpendicularmente a um espelho plano, obtenha-se o simétrico da figura em relação ao espelho. $\mathrm{O}$ espelho funciona como uma linha de simetria, e, dessa maneira, promovem-se situações de aprendizagem exploratórias de propriedades e conceitos geométricos. (BATISTELA, 2005, p. 29)
\end{abstract}

Em sua dissertação de mestrado, Batistela (2005) também registra informações sobre o caleidoscópio, apresentando referências históricas, afirmando o uso do mesmo como recurso didático na matemática. Três pesquisadores ${ }^{2}$ que apresentam estudos que utilizam os caleidoscópios são citados pela autora. Esses autores constataram que os espelhos e caleidoscópios, "são instrumentos que apoiam o trabalho do professor na tarefa de ensinar e estimulam a aprendizagem”. (BATISTELA, 2005, p. 12)

Para uma maior compreensão dos recursos pedagógicos citados anteriormente, buscou-se entender como são construídos e definidos os respectivos objetos. Almeida (2006) nos apresenta o que é um espelho, afirmando que.

os espelhos são produzidos por superfícies metálicas polidas. Nos espelhos comuns é a camada metálica (prata ou alumínio, por exemplo) que funciona como espelho, sendo em geral o vidro apenas um suporte e protetor. Conforme a natureza da superfície refletora, os espelhos podem ser classificados em: planos; esféricos; parabólicos; elíticos; cilíndricos; etc. (ALMEIDA, 2003, 26)

A maioria das pessoas tem conhecimento de que a reflexão em um espelho plano simples produz imagens idênticas, entretanto diferentes reflexões são produzidas com o uso de vários espelhos. Dessa forma, a combinação de espelhos produz o efeito da multiplicação da imagem, criando uma trama de imagens formadas pela conexão entre o ângulo dos

\footnotetext{
${ }^{2}$ Joana D'arc da Silva Reis utiliza os caleidoscópios generalizados fazendo parte de uma estratégia de ensino para apresentação de conceitos propriedades e objetos da geometria esférica; Flávio Roberto Gouvêa estuda a obtenção de fractais geométricos através de bases caleidoscópicas; e Marli Regina dos Santos investiga a utilização de caleidoscópios numa estratégia de ensino com jogos educacionais aplicados às tesselaçõesdo plano.
} 
espelhos e o número de imagens formadas.

Batistela (2005) ressalta que a primeira vez que se ouviu falar do caleidoscópio foi em 1817, quando um físico chamado David Brewster patenteou um "brinquedo" chamado caleidoscópio, cujo nome é derivado do grego, kalos (belo), eidos (aspecto) e skopien (ver). Foi criado para exibição de belas formas e as afirmações da autora se baseiam em resultado de seus estudos sobre a polarização dos raios de luz por múltiplas reflexões.

Em ROGER, (1824 apud BATISTELA, 2005, p. 34), o caleidoscópio é descrito como um “instrumento ótico, inventado por Sir David Brewster, que por um particular arranjo de espelhos, colocados em certa posição, produz combinações simétricas de imagens, notáveis pelas belas e infinitas variações possíveis.”

Logo, “um caleidoscópio nada mais é que um conjunto de dois ou mais espelhos planos perpendiculares a um mesmo plano que, quando algum objeto é colocado entre os espelhos, múltiplas imagens se formam.” (ALMEIDA, 2003, p. 23)

Tomando por base os conceitos acima apresentados pensou-se e estruturou-se o processo de construção dos recursos pedagógicos para alcançar os objetivos delineados. Assim, foram construídos espelhos articulados e caleidoscópios com bases triangulares, sendo um deles equilátero e, o outro, isósceles.

\section{Construindo com Matemática}

Para a construção dos caleidoscópios com bases triangulares, foram necessários alguns materiais: cola de silicone, papel contact e, ainda, seis lâminas de espelhos retangulares, com as seguintes medidas:

- 5 lâminas de $30 \mathrm{~cm}$ por $8 \mathrm{~cm}$;

- 1 lâmina de $30 \mathrm{~cm}$ por $6 \mathrm{~cm}$.

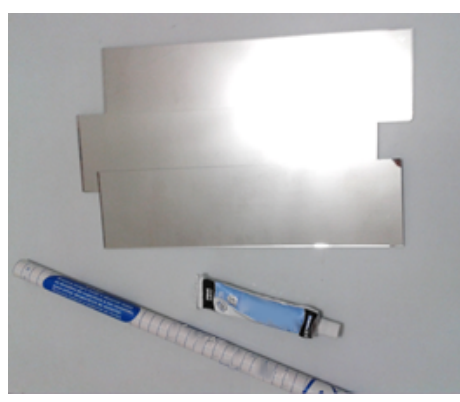

Material utilizado

Na sequencia a montagem dos dois caleidoscópios foi realizada fixando as lâminas com a cola de silicone, com as faces espelhadas voltadas para o interior. Importante deixar as lâminas bem rentes, podendo ser utilizado fita adesiva para segurá-las enquanto se introduz a 
cola.

Em seguida, envolveu-se o objeto com papel Contact, servindo para evitar que a luminosidade entrasse pelos vãos laterais.

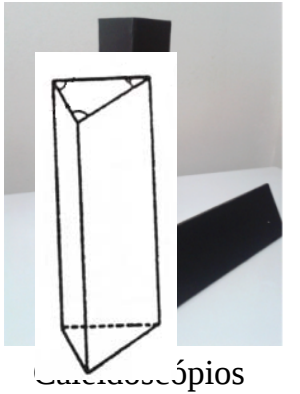

Estrutura do caleidoscópio

Para a construção dos espelhos articulados foram necessárias três lâminas de espelhos retangulares, com as seguintes medidas:

- 1 lâmina de $20 \mathrm{~cm}$ por $24 \mathrm{~cm}$;

- 1 lâmina de $20 \mathrm{~cm}$ por $32 \mathrm{~cm}$;

- 1 lâmina de $20 \mathrm{~cm}$ por $40 \mathrm{~cm}$.

Com o intuito de obter uma maior segurança e comodidade utilizou-se também supercola e MDF (placa de fibra de madeira), esta última utilizada para fixar os espelhos. Foi necessário providenciar o corte das placas de MDF do tamanho das lâminas de espelhos e em seguida prende-las com a supercola. Para facilitar a manipulação dos alunos foram colocadas cantoneiras de MDF atrás dos espelhos, como mostra a figura.

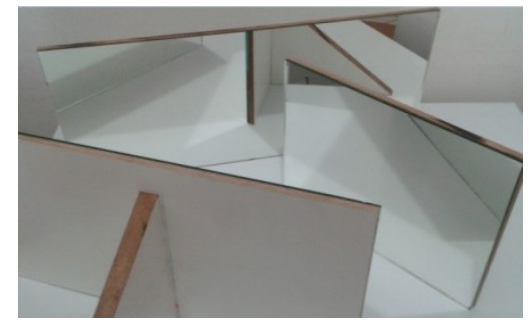

Espelhos planos e manipuláveis

Assim, a aula foi planejada conforme apresenta o mapa estrutural a seguir, que demonstra a organização da pesquisa relatada nesse artigo, destacando os principais elementos envolvidos no desenrolar desta proposta interdisciplinar até o desenvolvimento do problema de pesquisa anunciado. 


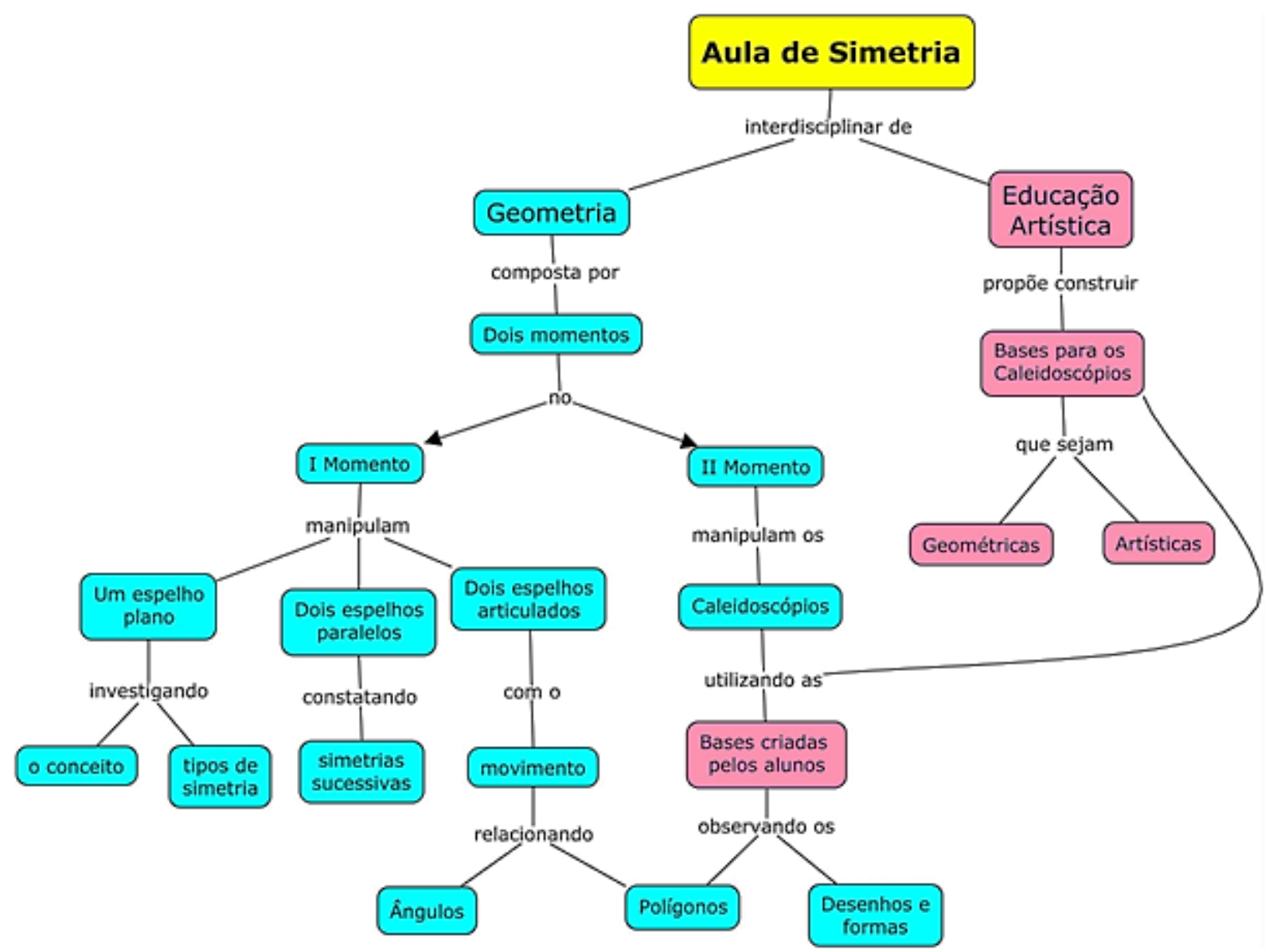

No que se refere aos caleidoscópios salientamos serem as bases figuras especialmente e intencionalmente construídas para gerar um visual pretendido. Assim, o primeiro passo foi dado pela professora de Educação Artística, que iniciou o trabalho com os alunos, instigando e orientando na constituição das bases.

\section{Dialogando com as Artes}

Com o intuito de atingir os objetivos desejados com a proposta foi entregue aos alunos, em uma folha sulfite, as bases triangulares com o tamanho apropriado que deveriam ter para satisfazer as necessidades dos caleidoscópios já criados, considerando serem duas bases, cada uma referente a cada caleidoscópio.

Em seguida, a professora de Educação Artística conduziu os alunos a seu foco, que era levá-los à construção das bases geométricas e artísticas, solicitando que, de forma livre e criativa, desenhassem em três das bases triangulares as figuras geométricas conhecidas, como polígonos (quadrado, triângulo, trapézio, losangos, etc.), círculos, ângulos, retas e pontos. 
Já na quarta base triangular foi solicitado aos alunos que realizassem um desenho de forma livre, orientando-os na parte artística do trabalho. Em média, foram utilizadas duas aulas para cada turma. O resultado da obra realizada na base foi entregue ao professor pesquisador, primeiro autor, evitando a perda do material.

Em uma entrevista realizada pelo professor pesquisador, a professora de Educação Artística relata que considera ser a noção simétrica muito importante para as Artes, alertando que nem todo trabalho deva ser simétrico, mas a simetria tem sido muito utilizada em suas aulas. A professora reafirma ainda que os alunos conseguem, por vezes, ter noção de figura simétrica, mas a palavra "simetria” e o seu significado muitas vezes não aparentam estar interrelacionados e assimilados.

Ainda em seu depoimento, a professora cita artistas que utilizam a simetria em seus trabalhos, como o pintor Rubem Valentim³ ${ }^{3}$ que possui trabalhos Artísticos com simetria. Com relação ao trabalho desenvolvido a professora considerou a aula muito interessante e o resultado foi por ela denominado por ‘fantástico', pois percebeu o benefício da aula quando os alunos observaram o próprio trabalho no caleidoscópio.

Além disso, a professora de artes observou que alguns alunos a surpreenderam na parte artística e aqueles que não haviam caprichado na elaboração das suas bases, se arrependeram quando as viram nos caleidoscópios, pois poderiam ter feito às formas com mais esmero, marcadas e contornadas, para que fosse possível perceber melhor a simetria.

A professora considera a interdisciplinaridade importante, especialmente quando se trata e de um conteúdo que pode ser utilizado com frequência em outros conteúdos. Em seu relato a professora afirma utilizar muito os conceitos de geometria em suas aulas, em especial o paralelismo e as figuras espaciais. Como sugestão para um próximo trabalho, a professora acredita ser capaz de aprimorar sua aula se abordar a simetria nas obras artísticas, antes de desenvolver o trabalho com as bases caleidoscópicas.

\section{Caminhando...}

No começo da aula, antes da abordagem de qualquer definição foi proposto um desafio de se colocar um espelho plano simples em determinado lugar da 'Figura 1' para tentar obter

\footnotetext{
${ }^{3}$ Rubem Valentim (1922 - 1991) foi pintor, escultor, gravador e professor brasileiro, considerado um dos grandes pintores construtivistas.
} 


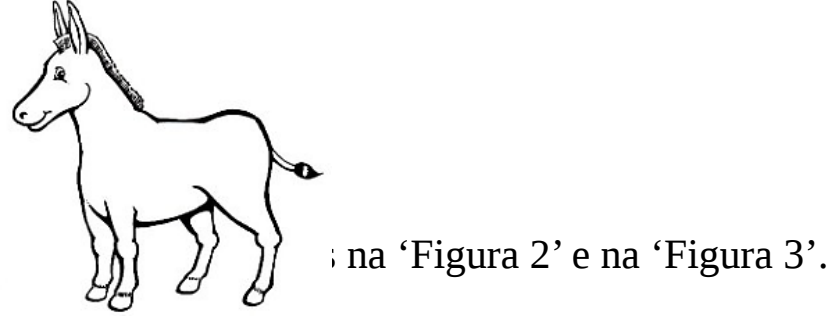

Figura 1

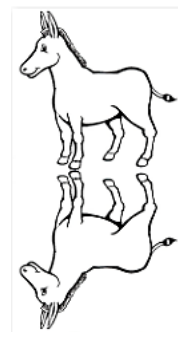

Figura 2

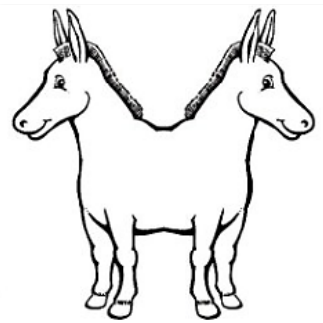

Figura 3

Esse desafio oportunizou circunstâncias adequadas e favoráveis para a prática de reconhecimento de figuras diferentes e seleção de partes de figuras congruentes a outras; A proposta foi propícia para a observação de propriedades de figuras geométricas e a exploração do conceito de simetria.

Para registrar e construir esse conceito recorreu-se à Teoria dos Registros de Representação Semiótica proposta por Duval. Segundo o autor, os registros de representação semiótica no ensino de geometria têm valorizado mais as representações mentais do que as semióticas, que por sua vez estão sendo deixadas de lado.

As representações mentais recobrem o conjunto de imagens e, mais globalmente, as
conceitualizações que um indivíduo pode ter sobre um objeto, sobre uma situação e
sobre o que lhe é associado. As representações semióticas são produções
constituídas pelo emprego de signos pertencentes a um sistema de representações
que tem inconvenientes próprios de significação e de funcionamento. Uma figura
geométrica, um enunciado em língua natural, uma fórmula algébrica, um gráfico são
representações semióticas que exibem sistemas semióticos diferentes. (DUVAL,
2012, p.269)

Vale ressaltar que as representações semióticas são essenciais à atividade cognitiva, isto é, são mais que uma forma de exteriorização de representações mentais, sendo necessárias além de outros meios de comunicação.

De acordo com Duval, para que um sistema semiótico possa ser um registro de representação, deve permitir as três atividades cognitivas fundamentais ligadas a semiose (apreensão ou a produção de uma representação semiótica). São elas: a formação de uma representação identificável como uma representação de um registro dado; o tratamento de uma representação e a conversão de uma representação.

A formação de uma representação identificável como uma representação de um registro dado torna necessária a seleção de relações e de dados no conteúdo a demonstrar. A formação do conceito de simetria começou com as figuras utilizadas no início da atividade. 
Em seguida, foram dispostas figuras e o professor solicitou à turma que fosse colocado o espelho plano onde se encontrava o(s) eixo(s) de simetria, para a busca de figuras com estrutura simétrica e contagem dos eixos de simetria. A seguir apresentamos algumas das imagens utilizadas.
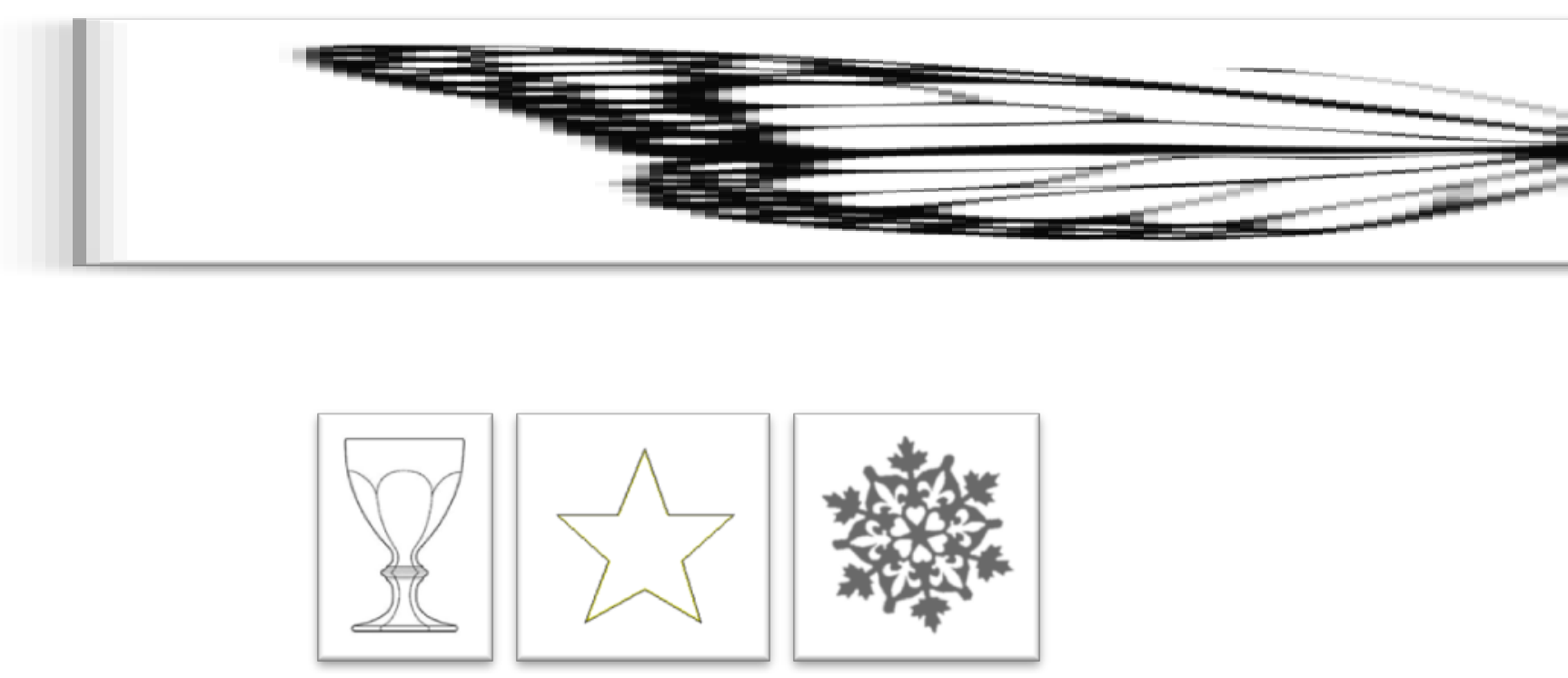

Logo, com esta dinâmica foi possível classificar o tipo de simetria segundo o número de eixos, como Simetria axial ou bilateral e simetria de rotação ou central. Assim, conseguiuse explicitar e abordar os conceitos de reflexão, rotação e de translação.

A segunda proposta deste primeiro momento incluiu o trabalho com dois espelhos planos e paralelos. Solicitou-se aos alunos que colocassem as figuras geométricas e/ou imagens entre os espelhos e verificassem a reflexão nos sentidos dos espelhos. Abaixo se apresenta uma imagem entre os espelhos.
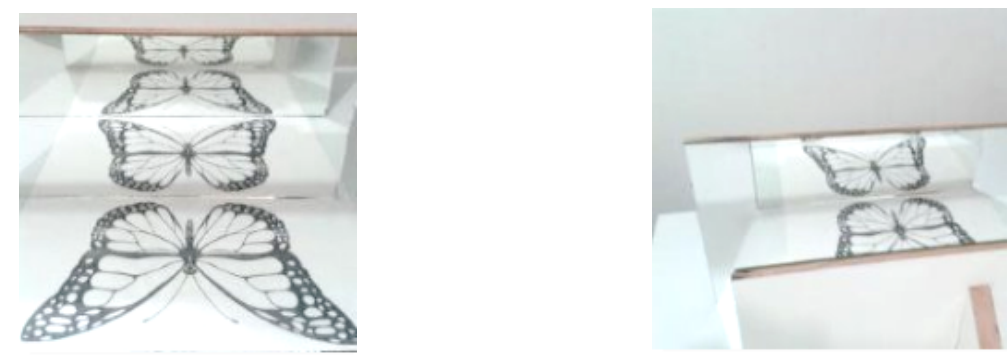

Nesse instante observaram-se as reflexões sucessivas dispostas nos espelhos, abordando os conceitos de translação e paralelismo. Quando dispostos os espelhos dessa forma pode-se notar um número infinito de imagens formadas entre os mesmos, como ilustrado na imagem anteriormente apresentada. 
A terceira proposta incluiu o trabalho com doi forma articulada, com um transferidor já desenhado em uma cartolina. Sejgicitou-se aos alunos que rotacionassem os espelhos sobre o transferidor, conferindo as possíveis figuras geométricas construídas, relacionando-as com o ângulo de abertura entre os espelhos.

Para uma melhor visualização colocou-se um papel sulfite entre os dois espelhos de maneira que o objeto e os espelhos formassem um polígono. Desta forma foi possível observar que polígonos regulares podem ser obtidos nas reflexões, os quais possuirão maior número de lados quanto menor for o ângulo central do polígono e vice-versa. A seguir a visualização de alguns polígonos construídos, com seus respectivos ângulos formados.

$190^{\circ}$

A variação do ângulo formado entre os espelhos é que determina a quantidade e a perfeição das imagens. Essa relação foi observada pelos alunos por meio de um processo investigativo orientado pelo professor. A tabela, a seguir, fornece algumas figuras geométricas que podem ser obtidas em função da variação do ângulo.

\begin{tabular}{|c|c|c|}
\hline ÂNGULOS & $\mathbf{N}^{\mathbf{0}}$ LADOS & POLÍGONO construído \\
\hline $120^{\circ}$ & 3 & Triângulo \\
\hline $90^{\circ}$ & 4 & Quadrilátero \\
\hline $72^{\circ}$ & 5 & Pentágono \\
\hline $60^{\circ}$ & 6 & Hexágono \\
\hline $51^{\circ} 3 / 7$ & 7 & Heptágono \\
\hline $45^{\circ}$ & 8 & Octógono \\
\hline $40^{\circ}$ & 9 & Eneágono \\
\hline $36^{\circ}$ & 10 & Decágono \\
\hline \multicolumn{2}{|c|}{ Fonte: Baseado em Alspaugh (1976 apud ALMEIDA, 2003, p. 31) }
\end{tabular}

Assim, ao visualizar os padrões simétricos para obtenção de polígonos, foi possível retomar os conceitos de ângulo, reflexão e rotação. A tabela acima foi desenvolvida como resultado da investigação proposta, arredondando os valores com os resultados fracionados. Com este resultado finalizou-se a primeira aula. 
Em um segundo momento, inici ntregue as bases triangulares aos alunos para aqueles que não haviam conplojídghon adbeazde Artes, pudessem concluir suas tarefas. Esse fato contribuiu para o desenvolvimento da aula, não dificultando a visualização nos caleidoscópios, pois enquanto alguns alunos os manipulavam, outros terminavam sua obra.

A atividade proposta foi identificar as figuras geométricas formadas nas bases construídas por cada aluno, além da base artística solicitada pela professora. A seguir, as imagens ilustram alguns resultados da criação dos alunos com as respectivas projeções no caleidoscópio.

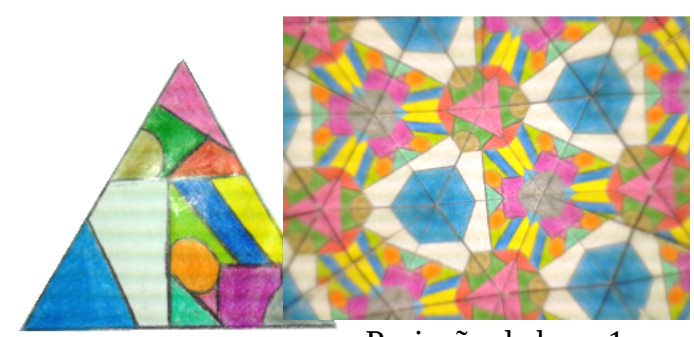

Base 1

Projeção da base 1

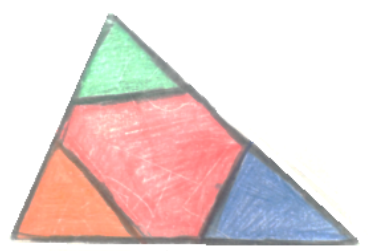

Base 2

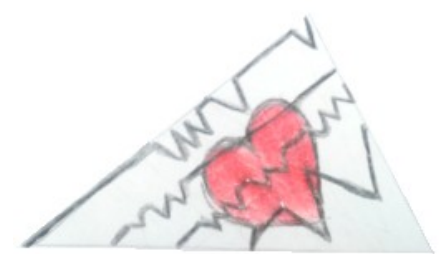

Base 3

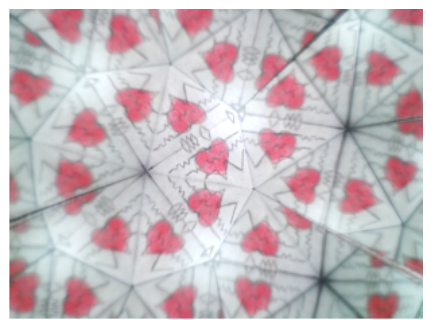

Projeção da base 3

Para facilitar a observação, o professor providenciou uma base de vidro e uma extensão elétrica com lâmpada para alocar abaixo do vidro. Assim, os alunos colocaram a folha em cima do vidro promovendo uma melhor visualização nos caleidoscópios. Com essa clareza de seus trabalhos desenvolvidos, os alunos se entusiasmaram em averiguar quais polígonos estavam sendo criados. 
A professora de Artes foi convidada a ver os resultados do trabalho desenvolvido nas aulas de artes nos caleidoscópios e analisou com os alunos o trabalho obtido. Percebeu-se nesse momento a presença de um diálogo entre áreas caracterizando a interdisciplinaridade, comentado por Carlos (2007).

\begin{abstract}
Há quem defenda que a interdisciplinaridade possa ser praticada individualmente, ou seja, que um único professor possa ensinar sua disciplina numa perspectiva interdisciplinar. No entanto, acreditamos que a riqueza da interdisciplinaridade vai muito além do plano epistemológico, teórico, metodológico e didático. Sua prática na escola cria, acima de tudo, a possibilidade do "encontro", da "partilha", da cooperação e do diálogo e, por isso, somos partidários da interdisciplinaridade enquanto ação conjunta dos professores. (CARLOS, 2007, p.168)
\end{abstract}

Nesse momento os alunos da turma, puderam observar tanto os aspectos geométricos, especialmente a formação de polígonos, quanto os aspectos artísticos, como o esquema de cores e traços. Foi uma partilha rica em trocas e diálogos, de forma que o trabalho realizado na aula de Educação Artística pode “refletir” na análise geométrica.

\title{
6. Considerações Finais
}

O relato de experiência, com características de um ensaio de pesquisa, apresentado nesse artigo não pode ser considerado pronto ou acabado. Trata-se de um processo de reflexão contínua sobre a prática docente no ensino da matemática. Ressaltamos que são inúmeras as contribuições dessa prática para a formação continuada do professor pesquisador. Espera-se que a divulgação dos resultados estimule não somente a formação dos professores envolvidos, mas também a de outros colegas de profissão.

Todos os instrumentos foram utilizados para explorar conceitos e propriedades geométricas de figuras que possuem linhas de simetria. Na primeira aula, foi possível notar um grande interesse dos alunos em manipular os espelhos e observar as reflexões. Como houve um rodízio entre os alunos, devido à aula ter poucos espelhos o manuseio dos objetos foi disputado.

Houve um grande êxito na construção e representação semiótica do conceito de simetria, evidenciando os critérios, como a formação da representação; o tratamento da representação e a conversão da mesma.

A manipulação dos espelhos articulados proporcionou uma investigação a qual os alunos perceberam uma relação entre o ângulo formado pelos espelhos (neste caso, é o ângulo 
central dos polígonos criados) e o número de lados do polígono obtido. Quanto maior o ângulo menor o número de lados do polígono ou o contrário, quanto menor o ângulo maior o número de lados do polígono.

Já na segunda aula, notou-se uma euforia nas duas turmas, pois todos queriam ver o efeito do caleidoscópio nas bases criadas por cada aluno. Inclusive os outros professores de matemática, as orientadoras, as vice-diretoras e até os professores de outras áreas (como educação física) se interessaram e foram ver o trabalho dos alunos, se encantando com o que havia sido desenvolvido.

Conforme citado anteriormente, os alunos que não haviam concluído suas bases na aula de Educação Artística foram orientados a terminá-las. Porém, com tamanha animação dos colegas que já haviam concluído suas bases, aqueles que ainda não haviam terminado titubeavam entre terminar seu trabalho e observar as bases dos colegas.

Algumas peculiaridades foram observadas, com alguns alunos do $8^{\circ} \mathrm{C}$ que, por iniciativa própria, começaram a manipular as bases criadas para o calidoscópio nos espelhos articulados de forma que ao movimentar as bases e os espelhos, conseguiam ver diferentes polígonos e formas. Alguns alunos dessa turma gostaram tanto do que produziram que tiraram fotos das projeções das suas bases no caleidoscópio e as dos colegas.

A turma do $8^{\circ} \mathrm{B}$, quase "atropelavam” uns aos outros para entrar primeiro na sala de vídeo, espaço onde ocorriam as aulas. A correria era só para se sentarem a frente e manipular os espelhos. Nessa turma não foi preciso o professor auxiliar os alunos a colocarem os caleidoscópios nas bases, pois eles próprios ajudavam uns aos outros a colocar e a observar os polígonos refletidos.

Dessa maneira, todos demonstraram em vários momentos interesse e atitudes reflexivas e criativas, principalmente nas ponderações dos resultados obtidos, evidenciando ser possível propor uma aula investigativa e manipulativa de forma interessante, envolvendo os alunos em aulas de simetria utilizando espelhos e caleidoscópios.

\section{Referências}


ALMEIDA, S. T. Um estudo de pavimentações do plano utilizando caleidoscópios e o software Cabri-Géomètre II. 2003. 147 f. Dissertação (Mestrado em Educação Matemática) - Instituto de Geociências e Ciências Exatas, Universidade Estadual Paulista, Rio Claro, 2003.

BATISTELA, Rosemeire de Fátima. Um Kit de espelhos planos para o ensino de geometria. 2005. iv, 134 f. Dissertação (mestrado) - Universidade Estadual Paulista, Instituto de Geociências e Ciências Exatas, 2005. Disponível em: http://hdl.handle.net/11449/91157.

BRASIL. Ministério da Educação. Secretaria de Educação Fundamental. Parâmetros Curriculares Nacionais: Matemática. ( $3^{\circ}$ e $4^{\circ}$ ciclos do ensino fundamental). Brasília: MEC, 1998.

CARLOS, Jairo Gonçalves.Interdisciplinaridade no Ensino Médio: desafios e potencialidades.2007. Dissertação (Mestrado profissional em Ensino de Ciências) Universidade de Brasília, UNB, Brasil. 2007.

DUVAL, R. Registros de representação semiótica e funcionamento cognitivo do pensamento. Tradução de MériclesThadeu Moretti. Revemat: R. Eletr. de Edu. Matem. Florianópolis, v. 07, n. 2, p.266-297, 2012.

MARTINS, R. A. Ensino-aprendizagem de geometria: uma proposta fazendo uso de caleidoscópios, sólidos geométricos e softwares educacionais. 2003. 246 f. Dissertação (Mestrado em Educação Matemática) - Instituto de Geociências e Ciências Exatas, Universidade Estadual Paulista, Rio Claro, 2003.

MURARI, C. Ensino-aprendizagem de geometria nas $7^{\text {a }}$ e $8^{\text {a }}$ séries, via caleidoscópios. 1999. 2 v. Tese (Doutorado em Educação Matemática) - Instituto de Geociências e Ciências Exatas, Universidade Estadual Paulista, Rio Claro, 1999. 